\title{
CALCULATION OF CRITICAL TEMPERATURES BY EMPIRICAL FORMULAE
}

The paper presents formulas used to calculate critical temperatures of structural steels. Equations that allow calculating temperatures $A c_{1}, A c_{3}, \mathrm{M}_{\mathrm{s}}$ and $B_{s}$ were elaborated based on the chemical composition of steel. To elaborate the equations the multiple regression method was used. Particular attention was paid to the collection of experimental data which was required to calculate regression coefficients, including preparation of data for calculation. The empirical data set included more than 500 chemical compositions of structural steel and has been prepared based on information available in literature on the subject.

Keywords: CCT diagram, modeling, heat treatment, steel

\section{Introduction}

Empirical formulas that allow calculating critical temperatures in steel based on mass concentrations of elements have been presented in scientific publications for many years. To elaborate the equations the multiple regression method is used. In most cases the general linear form of the model was applied. Calculated values of regression coefficients pointed to the influence of elements on temperature. One of the first models was published in 1944 by Payson and Savage [1]. The researchers used some results of research by Greninger [2], which concerned the influence of carbon on the martensitic transformation start temperature Ms and the work by Greninger and Troiano [3]. The work also analysed the influence of other elements. The research was conducted for seventeen types of steel with a chemical composition specifically selected for tests. Payson's and Savage's equation coefficients were corrected sequentially by Rowland and Lyle [4], and Nehrenberg [5]. A similar form of equation was proposed two years later by Grange and Stewart [6] who analysed the data available at that time. In subsequent years, formulas that enabled calculation of other critical temperatures in steels were presented a number of times. Among many works on the subject, one that is worth mentioning is the publication by Steven and Haynes, wherein the effect of chemical composition on the Ms temperature and the bainitic transformation start temperature Bs was analysed [7]. In his work Andrews published formulas that enable calculating the start temperature for the transformation from pearlite into austenite $\left(A c_{1}\right)$, and the finish temperature for the transformation from ferrite to austenite $\left(A c_{3}\right)$ [8]. The issue of modelling critical temperatures in steels was analysed in detail in papers $[9,10]$. Many of the empirical formulas available in literature was collected in the paper [11]. Other methods were also used for modelling critical temperatures in steels. These included artificial neural networks [12-17].

The paper presents results of original work related to the modelling of critical temperatures in steels using the multiple regression method. Formulas presented in the paper [17] were modified. This was made possible thanks to supplementing the set of empirical data.

\section{Data for calculations}

In modelling using the multiple regression method it is very important to prepare a representative set of empirical data. Data preparation was begun with the selection of independent variables representing the model. The selection of variables is the result of the knowledge of the modelling process. However, the availability of data often requires the adoption of necessary simplifications. Vectors that contain examples used in modelling should include the values of all variables. Simultaneously, the values of explanatory variables should evenly cover the entire field of the approximated function. An analysis of the range of values of independent variables, in which the developed models can be used, was carried out. Assessment of the distribution of values of explanatory variables was made based on descriptive statistics, cluster analysis and histograms made for one or two variables. An example of a diagram showing scatterplot matrix for the $\mathrm{Ac}_{3}$ temperature model is shown in the Fig. 1. For the same model, the Fig. 2 present examples of histograms showing the distribution of two elements: carbon and chromium as well as carbon and manganese.

\footnotetext{
SILESIAN UNIVERSITY OF TECHNOLOGY, INSTITUTE OF ENGINEERING MATERIALS AND BIOMATERIALS, 18A KONARSKIEGO STR., 44-100 GLIWICE, POLAND

Corresponding author: jacek.trzaska@polsl.pl
} 


\begin{tabular}{|c|c|c|c|c|c|c|c|}
\hline  & $\circ$ & 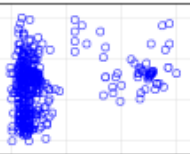 & 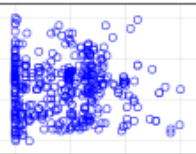 & 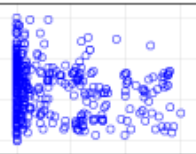 & 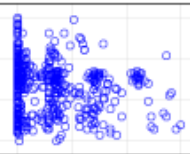 & 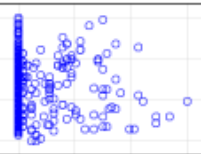 & 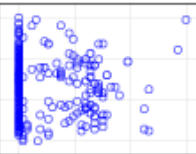 \\
\hline 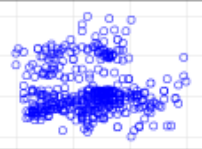 & $\mathrm{Mn}$ & & ofore & & क & $\begin{array}{l}\infty_{\infty} \\
\infty_{0} \\
\log _{\infty}\end{array}$ &  \\
\hline 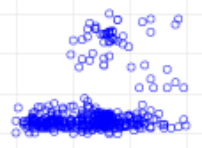 & $\begin{array}{r}0 \\
0 \\
0 \\
0\end{array}$ & $\mathrm{Si}$ & 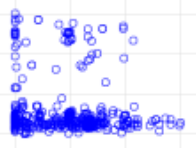 & 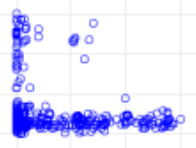 & $\begin{array}{ll}0 \\
8 \\
8\end{array}$ & 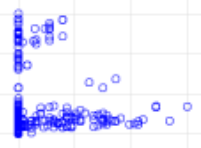 & 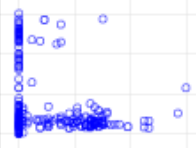 \\
\hline 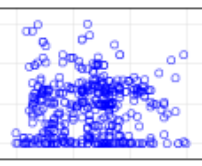 & \% & 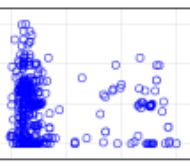 & $\square$ & 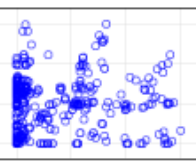 & 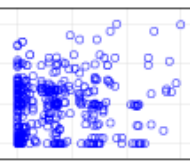 & 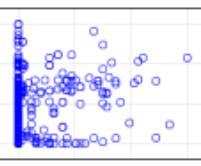 & 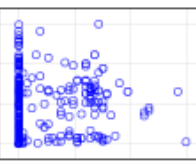 \\
\hline 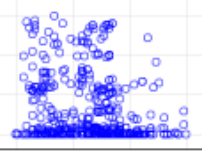 & ? & 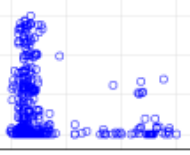 & 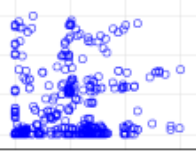 & $\mathrm{Ni}$ & 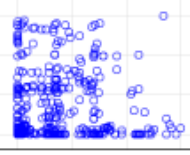 & 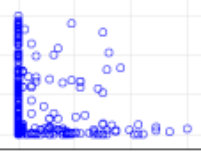 & 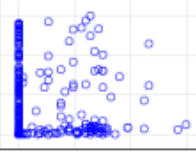 \\
\hline 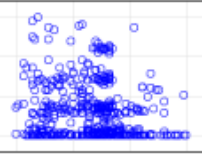 &  & 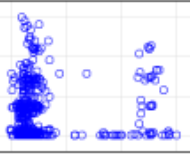 & 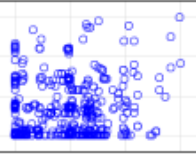 & 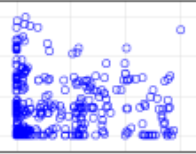 & Mo & 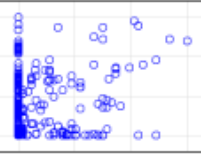 & 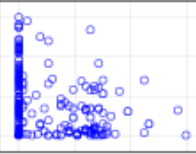 \\
\hline  & 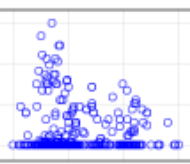 & 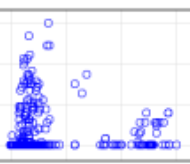 &  & 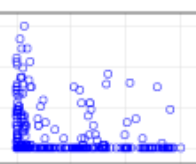 & 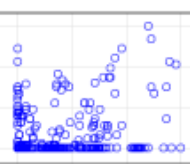 & V & 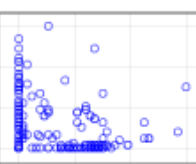 \\
\hline 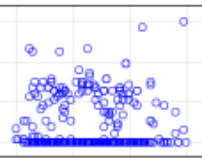 &  & 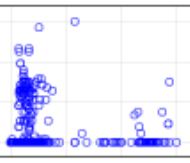 & 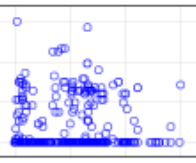 & 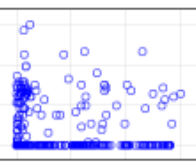 &  &  & $\mathrm{Cu}$ \\
\hline
\end{tabular}

Fig. 1. Scatterplot matrix for the $A c_{3}$ temperature model



a)

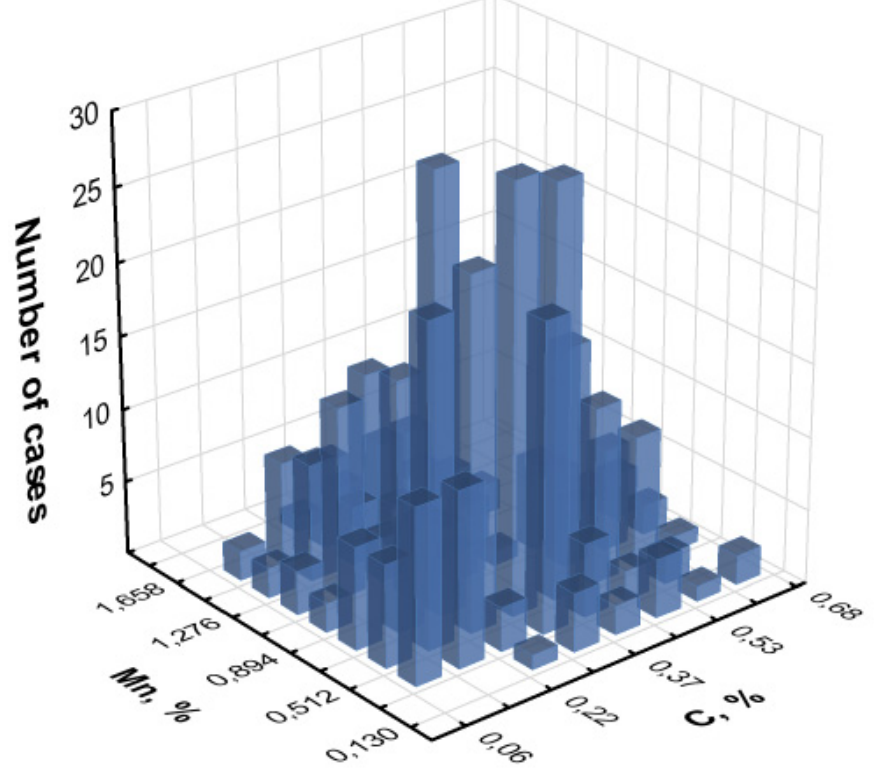

b)

Fig. 2. Histograms showing the distribution of mass concentration of elements: a) carbon and chromium, b) carbon and manganese 
Based on the conducted analyses the range of mass concentrations of elements, for which equation they can be applied, was determined. The minimum and maximum values are shown in Table 1. Moreover, additional conditions for the sums of concentrations of selected elements were defined (Table 2).

TABLE 1

Ranges of mass concentrations of elements

\begin{tabular}{|c|c|c|c|c|c|c|c|c|}
\hline \hline \multirow{2}{*}{ Range } & \multicolumn{10}{|c|}{ Mass fractions of elements, \% } \\
\cline { 2 - 10 } & $\mathbf{C}$ & Mn & Si & Cr & Ni & Mo & V & Cu \\
\hline min & 0.06 & 0.13 & 0.12 & 0 & 0 & 0 & 0 & 0 \\
\hline max & 0.68 & 2.04 & 1.75 & 2.30 & 3.85 & 1.05 & 0.38 & 0.38 \\
\hline average & 0.33 & 0.58 & 0.42 & 0.65 & 0.70 & 0.21 & 0.03 & 0.04 \\
\hline SD & 0.13 & 0.37 & 0.37 & 0.54 & 1.02 & 0.24 & 0.07 & 0.07 \\
\hline SD - standard deviation
\end{tabular}

TABLE 2

Additional conditions for limiting the scope of model application

\begin{tabular}{|c|c|c|c|c|}
\hline & \multicolumn{4}{|c|}{ Mass fractions of elements, \% } \\
\hline & $\mathbf{M n}+\mathbf{C r}$ & $\mathbf{M n}+\mathbf{C r}+\mathbf{N i}$ & $\mathbf{C r}+\mathbf{N i}$ & $\mathbf{M n}+\mathbf{~ N i}$ \\
\hline maximum & 3.6 & 5.6 & 5.3 & 4.5 \\
\hline
\end{tabular}

Among other assumptions concerning the variables attention was paid to the collinearity of explanatory variables. An adverse effect of multicollinearity occurs when the explanatory variables are intercorrelated. The influence of the explanatory variable on the explained variable contains the influence of all variables correlated with it. Multicollinearity may cause a false assessment of the significance of independent variables of the model and change the symbol of the regression coefficient. Multicollinearity was assessed based on the correlation matrix for the model variables and the Variance Inflation Factor (VIF). VIF statistics (1) characterizes the increase in variance caused by correlating the analysed explanatory variable with other independent variables.

$$
V I F_{i}=\frac{1}{1-R_{i}^{2}}
$$

where:

$R_{i}^{2}$ - determination coefficient for the $i^{\text {th }}$ independent variable, which acts as an explained variable in the auxiliary equation.

It is assumed that a moderate multicollinearity of explanatory variables occurs when the VIF $\geq 5$, while in the case of VIF $\geq 10$ strong multicollinearity is observed. [18] The values of the VIFs are summarized in Table 3. No multicollinearity was found for independent variables.

TABLE 3

The values of the Variance Inflation Factor

\begin{tabular}{|c|c|c|c|c|c|c|c|c|}
\hline \hline & \multicolumn{10}{|c|}{ Independent variables } \\
\cline { 2 - 9 } & $\mathbf{C}$ & $\mathbf{M n}$ & $\mathbf{S i}$ & $\mathbf{C r}$ & $\mathbf{N i}$ & $\mathbf{M o}$ & $\mathbf{V}$ & $\mathbf{C u}$ \\
\hline VIF & 1.13 & 1.34 & 1.11 & 1.26 & 1.26 & 1.15 & 1.15 & 1.05 \\
\hline
\end{tabular}

\section{Method and results}

Work on each model was initiated by determining a mathematical form. A general form of the equation was accepted:

$$
Y=a_{0}+\sum_{i} a_{i} f_{i}(X)
$$

where:

$Y$ - explained variable - transformation temperature; $a_{0}, a_{1} . . a_{i}-$ regression coefficients;

$f_{i}$ - functions of equation variables;

$X$ - vector of explanatory variables.

The equations were supplemented with additional components that took into account the interactions between explanatory variables. The interaction effect occurs when the influence of the explanatory variable on the explained variable changes with changes in the values of another explanatory variable. Products of two independent variables were introduced into the model. The estimation of regression coefficients for particular models was carried out using the least squares method.

Matching the equation to empirical data was assessed on the basis of the determination coefficient $\left(R^{2}\right)$. The value of the determination coefficient allows estimating what part of variability of the dependent variable is explained by independent variables. Changes in the values of the determination coefficient also depend on the number of independent variables. Adding the variable to the model increases the value of $R^{2}$ even if the explanatory variable is useless in the model. Therefore, to assess the significance of explanatory variables that were added or removed from the equation, the value of the adjusted determination coefficient was used. The adjusted $R^{2}$ coefficient is carried out due to the number of degrees of freedom, i.e. the number of observations reduced by the number of independent variables. The adjusted determination coefficient allows comparing multiple regression models with different numbers of explanatory variables that have been developed for the same empirical data. The lower value of the adjusted coefficient from the $R^{2}$ value suggests that the model may contain an insignificant explanatory variable.

The significance of regression coefficients for the model was tested by verifying hypotheses concerning individual $a_{i}$ coefficients in the form of a null hypothesis $\left(H_{0}: a_{i}=0\right)$, and an alternative hypothesis $\left(H_{a}: a_{i} \neq 0\right)$. The Student's t-distribution was used to verify the hypotheses. The testing statistics was calculated as the quotient of the regression coefficient and the standard error for this coefficient. The level of significance was $\alpha=0.05$. When the null hypothesis was rejected, the regression coefficient for the explanatory variable was considered statistically different from zero, assuming that the independent variable is statistically significant and influences the explained variable. The null hypothesis was rejected when the $p$-value, which was the calculated significance level for the testing statistics $t$, reached a lower value than 0.05 . Insignificant variables were removed from the equation, and then the regression coefficients were calculated once more.

Values of statistics for temperature models: $A c_{1}, A c_{3}, B_{s}$ and $M_{s}$ are presented in Table 4 . Table 4 shows the final part of the analysis after removing the insignificant variables. 
TABLE 4

Values of statistics used to evaluate the significance of regression coefficients

\begin{tabular}{|c|c|c|c|c|c|c|c|c|c|}
\hline Variable & Int. & $\mathrm{C}$ & $\mathrm{Mn}$ & $\overline{\mathrm{Si}}$ & $\mathrm{Cr}$ & $\mathrm{Ni}$ & Mo & $\mathrm{V}$ & $\mathrm{Cu}$ \\
\hline Model & \multicolumn{9}{|c|}{$A c_{1}$} \\
\hline $\mathrm{RC}$ & \begin{tabular}{|l|}
741.9 \\
\end{tabular} & -29.1 & -14.0 & 12.6 & 15.9 & -16.8 & -16.2 & 45.2 & \begin{tabular}{|l|}
36.3 \\
\end{tabular} \\
\hline $\begin{array}{c}\text { Standard } \\
\text { error }\end{array}$ & 3.5 & 5.7 & 2.2 & 2.0 & 1.4 & 0.8 & 3.1 & 11.3 & 9.8 \\
\hline$t$ Stat & 212.3 & -5.1 & -6.4 & 6.4 & 11.0 & -21.9 & -5.2 & 4.0 & 3.7 \\
\hline$p$-value & 0 & $5 \mathrm{E}-7$ & $4 \mathrm{E}-10$ & $4 \mathrm{E}-10$ & $2 \mathrm{E}-25$ & $7 \mathrm{E}-75$ & $2 \mathrm{E}-7$ & $8 \mathrm{E}-5$ & $2 \mathrm{E}-4$ \\
\hline Model & \multicolumn{9}{|c|}{$A c_{3}$} \\
\hline $\mathrm{RC}$ & \begin{tabular}{|l|}
924.7 \\
\end{tabular} & $-219.4 *$ & -6.9 & 39.2 & - & -15.9 & 13.4 & 97.0 & - \\
\hline $\begin{array}{c}\text { Standard } \\
\text { error }\end{array}$ & 5.2 & 7.3 & 2.5 & 2.3 & - & 0.9 & 3.5 & 13.6 & - \\
\hline$t$ Stat & \begin{tabular}{|l|}
176.4 \\
\end{tabular} & -29.9 & -2.8 & 16.7 & - & -18.1 & 3.8 & 7.1 & - \\
\hline$p$-value & 0 & $3 \mathrm{E}-111$ & 0.006 & $2 \mathrm{E}-49$ & - & $4 \mathrm{E}-56$ & 0.0001 & $4 \mathrm{E}-12$ & - \\
\hline Model & \multicolumn{9}{|c|}{$B_{s}$} \\
\hline $\mathrm{RC}$ & \begin{tabular}{|l|}
770.9 \\
\end{tabular} & \begin{tabular}{|l|}
-231.5 \\
\end{tabular} & \begin{tabular}{|l|}
-68.7 \\
\end{tabular} & \begin{tabular}{|l|}
-23.3 \\
\end{tabular} & \begin{tabular}{|l|}
-58.5 \\
\end{tabular} & \begin{tabular}{|l|}
-30.8 \\
\end{tabular} & \begin{tabular}{|l|}
-55.4 \\
\end{tabular} & \begin{tabular}{|l|}
-41.3 \\
\end{tabular} & - \\
\hline $\begin{array}{c}\text { Standard } \\
\text { error }\end{array}$ & 6.9 & 10.6 & 4.1 & 3.6 & 2.6 & 1.4 & 5.4 & 19.8 & - \\
\hline$t$ Stat & \begin{tabular}{|l|}
112.4 \\
\end{tabular} & -21.9 & -16.8 & -6.5 & -22.3 & -22.3 & \begin{tabular}{|l|}
-10.3 \\
\end{tabular} & -2.1 & - \\
\hline$p$-value & 0 & $1.1 \mathrm{E}-7$ & $6 \mathrm{E}-50$ & $2 \mathrm{E}-10$ & $2 \mathrm{E}-75$ & $2 \mathrm{E}-75$ & $1 \mathrm{E}-22$ & 0.04 & - \\
\hline Model & \multicolumn{9}{|c|}{$M_{s}$} \\
\hline $\mathrm{RC}$ & 541.2 & \begin{tabular}{|l|}
-401.2 \\
\end{tabular} & -35.6 & -10.5 & -14.2 & -18.1 & -17.1 & - & - \\
\hline $\begin{array}{c}\text { Standard } \\
\text { error }\end{array}$ & 4.7 & 7.6 & 2.9 & 2.4 & 1.8 & 0.9 & 3.4 & - & - \\
\hline$t$ Stat & 115.8 & -52.6 & -12.3 & -4.4 & -7.7 & -18.7 & -5.01 & - & - \\
\hline$p$-value & 0 & $8 \mathrm{E}-205$ & $2 \mathrm{E}-30$ & $1 \mathrm{E}-05$ & $5 \mathrm{E}-14$ & $1 \mathrm{E}-59$ & $7 \mathrm{E}-7$ & - & - \\
\hline
\end{tabular}

The statistical significance of the regression model was examined using the $F$ test. The testing statistic with the $F$-FisherSnedecor distribution was calculated as the quotient of the mean value of the regression squares, and the mean square error taking into account the degrees of freedom. The null and alternative hypotheses were verified. Accepting the null hypothesis means that there is no dependence between the set of explanatory variables and the explained variable. The alternative hypothesis for the $F$ test that confirmed the statistical significance of at least one regression coefficient was assumed when the $p$-value was lower than 0.05 . Table 5 summarizes the statistics for the $F$ test supplemented with, among others, the values of the standard error, the correlation coefficient $(R)$, the determination coefficient $R^{2}$ and the adjusted determination coefficient.

TABLE 5

Values of statistics used to evaluate the significance of the developed models

\begin{tabular}{|c|c|c|c|c|}
\hline \multirow{2}{*}{} & \multicolumn{4}{|c|}{ Model } \\
\cline { 2 - 5 } & $\boldsymbol{A c}_{\boldsymbol{1}}$ & $\boldsymbol{A c}_{\boldsymbol{3}}$ & $\boldsymbol{B}_{\boldsymbol{s}}$ & $\boldsymbol{M}_{\boldsymbol{s}}$ \\
\hline$R$ & 0.78 & 0.86 & 0.87 & 0.93 \\
\hline$R^{2}$ & 0.61 & 0.75 & 0.75 & 0.87 \\
\hline Adjusted $R^{2}$ & 0.61 & 0.75 & 0.75 & 0.86 \\
\hline Standard error & 15.55 & 17.80 & 27.53 & 19.99 \\
\hline Observations & 500 & 484 & 476 & 502 \\
\hline Significance $F$ & $1.14 \mathrm{E}-96$ & $3 \mathrm{E}-140$ & $9 \mathrm{E}-138$ & $1 \mathrm{E}-212$ \\
\hline
\end{tabular}

The elaborated models were also assessed on the basis of: the mean absolute error, the standard error deviation, and the standard deviation quotient of the calculation error, as well as the standard deviation of the dependent variable value. The standard deviation quotient allows referring the error value of the model to the scope of changes of the dependent variable. The ,ideal“ value for this statistic is 0 .

Table 6 shows the following values: the mean absolute error, the standard error deviation, and the standard deviation quotients for error and empirical values of the dependent variable.

TABLE 6

Values of statistics used to evaluate the quality of the developed models

\begin{tabular}{|c|c|c|c|}
\hline \hline & $\begin{array}{c}\text { Mean absolute } \\
\text { error, }{ }^{\circ} \mathrm{C}\end{array}$ & $\begin{array}{c}\text { Standard deviation } \\
\text { of the error, }{ }^{\circ} \mathrm{C}\end{array}$ & $\begin{array}{c}\text { Ratio of standard } \\
\text { deviations }\end{array}$ \\
\hline$A c_{1}$ & 12.4 & 9.2 & 0.36 \\
\hline$A c_{3}$ & 14.1 & 10.7 & 0.30 \\
\hline$B_{S}$ & 21.2 & 17.2 & 0.31 \\
\hline$M_{S}$ & 14.8 & 13.3 & 0.24 \\
\hline
\end{tabular}

When applying the presented procedure, equations that explain the dependence between the chemical composition of steel and transformation temperatures were elaborated: $A c_{1}, A c_{3}$, $B_{s}$ and $M_{s}$. Critical temperatures models are shown in equations (3)-(6).

$$
\begin{aligned}
A c_{1}= & 742-29 \cdot \mathrm{C}-14 \cdot \mathrm{Mn}+13 \cdot \mathrm{Si}+ \\
+ & 16 \cdot \mathrm{Cr}-17 \cdot \mathrm{Ni}-16 \cdot \mathrm{Mo}+45 \cdot \mathrm{V}+36 \cdot \mathrm{Cu} \\
A c_{3}= & 925-219 \cdot \sqrt{\mathrm{C}}-7 \cdot \mathrm{Mn}+ \\
& +39 \cdot \mathrm{Si}-16 \cdot \mathrm{Ni}+13 \cdot \mathrm{Mo}+97 \cdot \mathrm{V} \\
B_{S}= & 771-231.5 \cdot \mathrm{C}-69 \cdot \mathrm{Mn}-23 \cdot \mathrm{Si} \\
& -58,5 \cdot \mathrm{Cr}-31 \cdot \mathrm{Ni}-55 \cdot \mathrm{Mo}-41 \cdot \mathrm{V} \\
M_{S}= & 541-401 \cdot \mathrm{C}-36 \cdot \mathrm{Mn} \\
& -10,5 \cdot \mathrm{Si}-14 \cdot \mathrm{Cr}-18 \cdot \mathrm{Ni}-17 \cdot \mathrm{Mo}
\end{aligned}
$$

For critical temperature models the following scatter plots for dependent variable values that were experimental and calculated using equations (3-6) were made. The results are shown in Fig. 3.

\section{Summary}

The paper presents equations describing the dependence between the chemical composition of steel and the start temperature for the transformation from pearlite into austenite $\left(A c_{1}\right)$, the finish temperature for the transformation from ferrite into austenite $\left(A c_{3}\right)$, the bainitic transformation start temperature $\left(B_{S}\right)$, and the martensitic transformation start temperature $\left(M_{s}\right)$.

The theory of correlation and regression is a useful tool to determine the degree of connection of variables in a model. It allows answering the question whether there is a dependence 



Experimental temperature, ${ }^{\circ} \mathrm{C}$
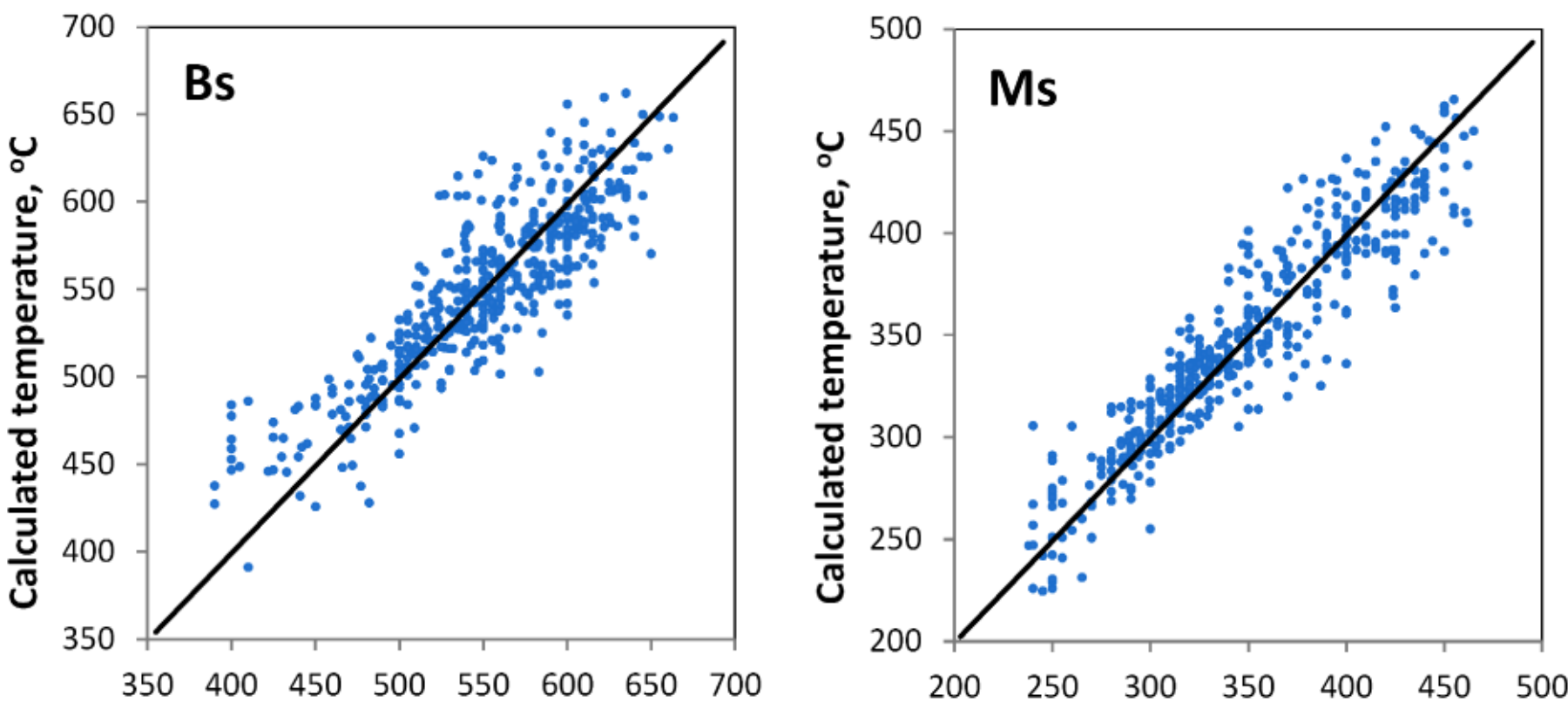

Experimental temperature, ${ }^{\circ} \mathrm{C}$

Experimental temperature, ${ }^{\circ} \mathrm{C}$

Fig. 3. Comparison of the experimental temperatures with values calculated using the regression model

between variables and whether it is close. Moreover, the equations can be easily spread and widely used, as well as verified by other research results. A certain piece of information on the dependence between the explanatory variables and the explained variable is visible in the form of values of coefficients of the regression equation. The value of the regression coefficient may not always be interpreted as the force of influence of an element on the value of transformation temperature. It should be remembered that there is variability in the explanatory variable and the values of other independent variables.

The set of empirical data has essential meaning for the quality of the developed models. The set was used to calculate the regression coefficients. The presented equations can be used only in the range of concentrations of alloying elements shown in the Table 1. Simultaneously, the conditions set out in the Table 2 should be complied with.

The multiple regression and logistic regression methods were also used to develop other models that describe the transformation temperatures as a function of the cooling rate, hardness of steel and volume fractions of ferrite, pearlite, bainite and martensite in the microstructure of steel. The results are shown in papers [19-21]. 


\section{Acknowledgements}

The publication was partially financed by a statutory grant of the Faculty of Mechanical Engineering at the Silesian University of Technology in 2015.

\section{REFERENCES}

[1] P. Payson, C.H. Savage, Martensite Reactions in Alloy Steels, Transactions ASM 33, 261-275 (1944).

[2] A.B. Greninger, The Martensite Thermal Arrest in Iron-Carbon Alloys and Plain Carbon Steels, Transactions ASM 30, 1-26 (1942).

[3] A.B. Greninger, AR Troiano, Kinetics of the Austenite to Martensite Transformation in Steel, Transactions ASM 28, 537-574 (1940).

[4] Transactions ASM 37, 27-47 (1946).

[5] A.E. Nehrenberg, The Temperature Range of Martensite Formation, Transactions AIME 167, 494-498 (1946).

[6] R.A. Grange, H.M. Stewart, The Temperature Range of Martensite Formation, Transactions AIME 167, 467-490 (1946).

[7] W. Steven, A.G. Haynes, The temperature of formation of martensite and bainite in low-alloy steels. Some effects of chemical composition, Journal of the Iron and Steel Institute 183, 349-359 (1956).

[8] K.W. Andrews, Empirical formulae for the calculation of some transformation temperatures, Journal of the Iron and Steel Institute 203, $721-727$ (1965).

[9] B. Pawłowski, Temperatury krytyczne w stalach, Wydawnictwa AGH, Kraków (2012).

[10] B. Pawłowski, Critical points of hypoeutectoid steel - prediction of the pearlite dissolution finish temperature $\mathrm{Ac}_{1 \mathrm{f}}$, Journal of Achievements in Materials and Manufacturing Engineering 49(2), 331-337 (2011).

[11] A.A. Gorni, Steel Forming And Heat Treating Handbook, 2015, http://www.gorni.eng.br/e/Gorni_SFHTHandbook.pdf
[12] T. Sourmail, C. Garcia-Mateo, A model for predicting the Ms temperatures of steels, Computational Materials Science 34, 213218 (2005).

[13] W. Vermeulen, P.F. Morris, A.P. De Weijer, S. Van der Zwaag, Prediction of martensite start temperature using artificial neural networks, Ironmaking and Steelmaking 23(5), 433-437 (1996).

[14] C. Garcia-Mateo, C. Capdevila, F. Garcia Caballero, C. Garcia de Andres, Artificial neural network modeling for the prediction of critical transformation temperatures in steels, Journal of Materials Science 42(14), 5391-5397 (2007).

[15] L.A. Dobrzański, J. Trzaska, Application of neural network for the prediction of continuous cooling transformation diagrams, Computational Materials Science 30(3-4), 251-259 (2004).

[16] L.A. Dobrzański, J. Trzaska, Application of neural networks for prediction of critical values of temperatures and time of the supercooled austenite transformations, Journal of Materials Processing Technology 155-156, 1950-1955 (2004).

[17] J. Trzaska, L.A. Dobrzański, Modelling of CCT diagrams for engineering and constructional steels, Journal of Materials Processing Technology 192-193, 504-510 (2007).

[18] D.T. Larose, Data mining methods and models, John Wiley \& Sons (2006).

[19] J. Trzaska, Calculation of the steel hardness after continuous cooling, Archives of Materials Science and Engineering 61(2), 87-92 (2013).

[20] J. Trzaska, Calculation of volume fractions of microstructural components in steels cooled from the austenitizing temperature, Journal of Achievements in Materials and Manufacturing Engineering 65(1), 38-44 (2014). 